\title{
Impacts of fluvial processes on medieval settlement Lukovskoe (Tatarstan, Russia)
}

\author{
Artur Gafurov $^{1}$, Iskander Gainullin ${ }^{2}$, Bulat Usmanov ${ }^{1,3}$, Petr Khomyakov ${ }^{1}$, and Alexey Kasimov ${ }^{3}$ \\ ${ }^{1}$ Institute of Environmental Sciences, Kazan Federal University, Kazan, 420008, Russia \\ ${ }^{2}$ Institute of archaeology. A. H. Khalikov, Academy of Sciences of the Republic of Tatarstan, \\ Kazan, 420012, Russia \\ ${ }^{3}$ SRL "Interdisciplinary Innovative and Scientific-Practical Archaeological and Ethnological Research", \\ Kazan Federal University, Kazan, 420008, Russia \\ Correspondence: Artur Gafurov (gafurov.kfu@gmail.com) \\ Published: 1 August 2019
}

\begin{abstract}
This work is continuation of the research aimed at developing of a system for analysing of risks of destruction of archaeological objects of Volga-Bulgaria period (X-XIII centuries AD) on the territory of the Republic of Tatarstan. Most of the Volga-Bulgaria settlements located on the small rivers banks. This fact is determining the risk of their destruction by natural processes. In order to identify the risk of transformation of archaeological sites by fluvial processes bank erosion dynamics at Lukovskoe fortified settlement evaluated. Modern field survey with use of UAV and GNSS methods applied to study the relief of monument territory. The measured data were analysed using the Geographical Information System (GIS) to evaluate intensity of bank erosion. Historical maps, archival remote sensing data and actual orthophotoplans compared to get quantitative characteristics of monument territory damage. The main factors that influence bank erosion at Lukovskoe fortified settlement placement are the meandering of the Kubnya riverbed, bank height and the ground that forms it. This study shows that remote sensing and 3-D-modelling on the base of UAV survey is very important in study of fluvial processes dynamics as a factor of archaeological objects destruction. The results of research will help to identify trends in monuments state and to quantify the risks of their destruction.
\end{abstract}

\section{Introduction}

The state of archaeological sites consists of interacting natural and anthropogenic components that form under the influence of human activity and natural processes over time. To characterize the effects of natural processes on the current state of medieval sites, the most recent interdisciplinary methods and technologies are required (Gainullin et al., 2017). Accordingly, the development of cultural heritage preservation strategies based on advanced methods is an essential part of modern archaeological research (Nicu, 2018).

Remote sensing, geo-informatics and field survey methods can be used to evaluate spatial and temporal changes in landscapes and related historical sites. These analytical methods provide quantitative assessments of impact of natural hazards and the risks of related processes on archaeological sites.
Notably, multitemporal aerial and satellite imagery are widely used in the preservation assessment of historical and cultural heritage objects (Gainullin et al., 2017). Increasingly, unmanned aerial vehicles (UAV) are being used to conduct remote surveys of local archaeological objects and create 3-D-models (Fernandez-Hernandez et al., 2015). The use of high-precision geodetic equipment is common and essential for the study of archaeological sites. For example, geodesic methods, such as GNSS technology (Gafurov, 2018), topographic survey with total station (Usmanov et al., 2018) and laser scanning equipment (Usmanov et al., 2015; Yermolaev et al., 2018) have been used to evaluate the dynamics and effects of exogenous processes that threaten monuments. Thus, the use of modern technologies provides accurate data collection, help to build complex multi-layer maps and form archaeological objects geodatabases. 


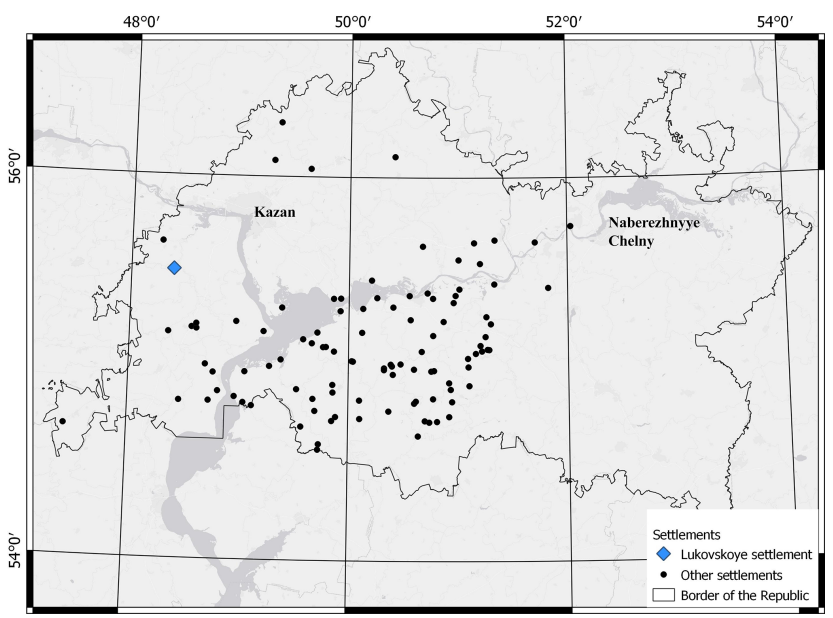

Figure 1. Study area.

In 2017, 2751 objects of cultural heritage (historical and cultural monuments) were under the influence of natural and anthropogenic factors in Republic of Tatarstan (RT), Russia. Accordingly, the loss of such artefacts will have implications for the historical legacy of the Tatarstan people. The last detailed study of archaeological monuments of Tatarstan was conducted in the 1970s and more recent investigation of these archaeological heritage sites of significance is necessary.

The Republic of Tatarstan is located in the eastern part of the East European Plain, near the confluence of Volga and Kama rivers (Fig. 1) and covers, an area of $68000 \mathrm{~km}^{2}$. The average elevation is $170 \mathrm{~m}$ above sea level but some areas rise to $300-350 \mathrm{~m}$. The study area is located on the east European Plain that rises from the Volga River to the spurs of the Ural Mountains. Erosional features in the landscape formed by flowing water include gullies and ravines that dissect the slopes of uplands and river valleys. Four main large rivers (Volga, Kama, Belaya and Vyatka) and an additional 500 small rivers over $10 \mathrm{~km}$ in length transect this region. Many of the prominent archaeological sites in this region are located on the banks and terraces of small rivers (Yermolaev et al., 2012).

The goal of this study is to develop a system to evaluate the potential risk of fluvial processes of impacting archaeological objects of Volga-Bulgaria that were constructed for the period (X-XIII centuries AD) in Tatarstan. Here, defensive fortifications (shafts, ditches), are examined because they are easily identified using aerial survey data. The present study reports the effects of riverbed dynamics on a Lukovskoe fortified settlement.

\section{Materials and methods}

An evaluation of riverbed dynamics in this study was evaluated using GIS and remote sensing techniques described by Ivanov et al. (2017). In addition, historical maps, topograph- ical maps, aerial images (Soviet aerial images from 1958 and 1980) and field surveys with UAV and GNSS were used to other important information which was used in an integrated GIS database. For a better understanding of the fortification system, river dynamics and negative exogenous processes, a 3-D model was developed using UAV photos made during fieldwork in 2017 and 2018. The model was created using AgiSoft Photoscan software. The procedure involved the following stages:

1. Gathering the information - dedicated literature, cartographic sources, archive data, RS data, aerial and satellite photographs, on-site photographs;

2. Field surveys - specification of location and visual features of settlement; photo identification of current monument state; GNSS survey of reference points; aerial survey of archaeological object under study.

Aerial photographs of the area were produced with a multi-rotor UAV DJI Phantom 4 using a 12-megapixel camera mounted on a quadrocopter. A smartphone using DronDeploy software Aerial photography was performed with the following parameters: - height -50 $100 \mathrm{~m}$; - pictures overlapping - 60\%-80\%; - camera position $-90^{\circ}$; - coverage - area survey; - meteorological conditions - no precipitation, wind no more than $15 \mathrm{~m} \mathrm{~s}^{-1}$.

Coordinates in plan and height during aerial survey were determined using GPS built in the UAV. This accuracy $(4-5 \mathrm{~m})$ is not sufficient for the construction of a topographic plan, digital terrain model (DTM) and digital elevation model (DEM) of an archaeological heritage object. To increase the accuracy of the survey before the flight, a network of control points was identified banner fabric with holes in the corners to fix geodetic pole with antenna. For high precision coordinates and height detection, a double frequency GNSS receiver with external antenna and GCPs centres were used. The survey was performed in Real Time Kinematics (RTK) regime in World Geodetic System 84 (WGS84) with real-time corrections by satellite reference stations. Coordinates of the GCPs centers improved UAV data processing accuracy.

3. Office analysis - all the maps and aerial photos were georeferenced to identify the most dynamic areas prone to river erosion, to identify the stages of archaeological heritage destruction, and 3-D modelling.

Photogrammetric works were performed in Agisoft Photoscan in the following sequence: - images inspection; - pictures alignment; - cloud of points construction; - digital elevation model and orthophoto construction.

DEM analysis, mapping and calculations were conducted in Golden Software Surfer 13 software. A digital 
terrain model (DTM) with a step of $0.5 \mathrm{~m}$ showing the altitude characteristics of the settlement territory was generated by the point cloud. Profiles, inclination and aspect maps described the morphometric characteristics of settlement relief. Ultra-high resolution orthophotos with a pixel size of $5 \mathrm{~cm}$ permitted creation of electronic layers for topographic plans to be constructed in MapInfo Professional 15.0 software.

\section{Results and discussion}

Lukovskoe (Yapanchino) fortified settlement (Fig. 2) dates from two periods in the history of Volga Bulgaria - preMongol and Golden Horde (XII-XIV centuries). The hillfort was built in the XII century and inhabited until the XIV century (Gubaidullin, 2017). The settlement was first described by Vyacheslav who noted “... fortified settlements, burial mounds and other ancient earth mounds in Kazan governorate" (Vyacheslav, 1874). In 1877, Shpilevsky noted that the territory of the Lukovskoe settlement was plowed. In 1891 and 1909, Akhmarov examined the settlement and noted the plowing of the archaeological site, which allowed him to collect a rich material. He notes the destruction of the monument from the south and west under the influence of Kubnya river, "the area of the settlement decreases every year". Akhmarov determined the length of the shafts - 110 fathoms (about 240 m) (Akhmarov, 1894, 1910). In 1950, Kalinin investigated the settlement and reported the area of the monument was $23000 \mathrm{~m}^{2}$ and that fortifications had shortened by $40 \mathrm{~m}$ since the 1891 survey (Kalinin, 1954). In the 80s-90s of the 20th century, the fortifications of the Lukovskoe settlement were examined by archaeological expeditions of Iskander Lerunovich Izmailov and Airat Maratovich Gubaidullin. By comparison with the data of Nikolay Filippovich Kalinin expedition monument area significantly decreased due to continuous riverbank caving (Gubaidullin, 2017).

Thus, the results of field studies for almost 130 years indicate both the anthropogenic impact on the territory of the monument and its destruction due to the dynamics of the Kubnya river.

UAV surveys (2017, 2018), orthophotos (2017) and aerial photographs (1958) improved identification of changes in landscape. For 59 years, significant changes caused by riverbed displacement occurred in the study area (Fig. 3).

The site and the fortifications was previously destroyed as a result of channel deformations from the northern side, as evidenced by the presence of a crescent lake. Its convex side, on which the main energy of the stream falls, is directly adjacent to the territory of the settlement and forms a ledge. This is confirmed by literary sources, which describes the destruction of the settlement by fluvial processes and indicates the change of fortifications length $-240 \mathrm{~m}$ in 1891 (Akhmarov, 1894), in 1950-200 m (Kalinin, 1954). By the middle of the

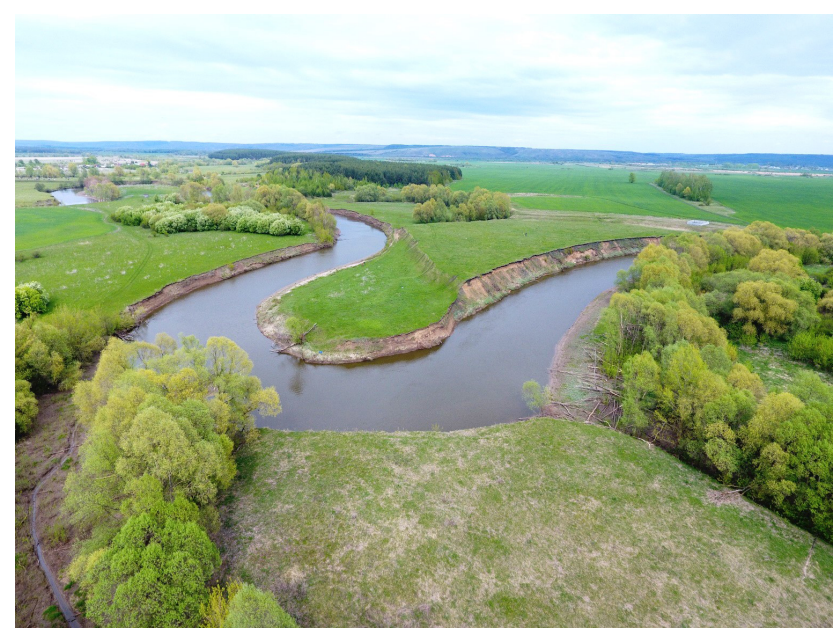

Figure 2. Location of the Lukovskoe fortified settlement on the Kubnya river.

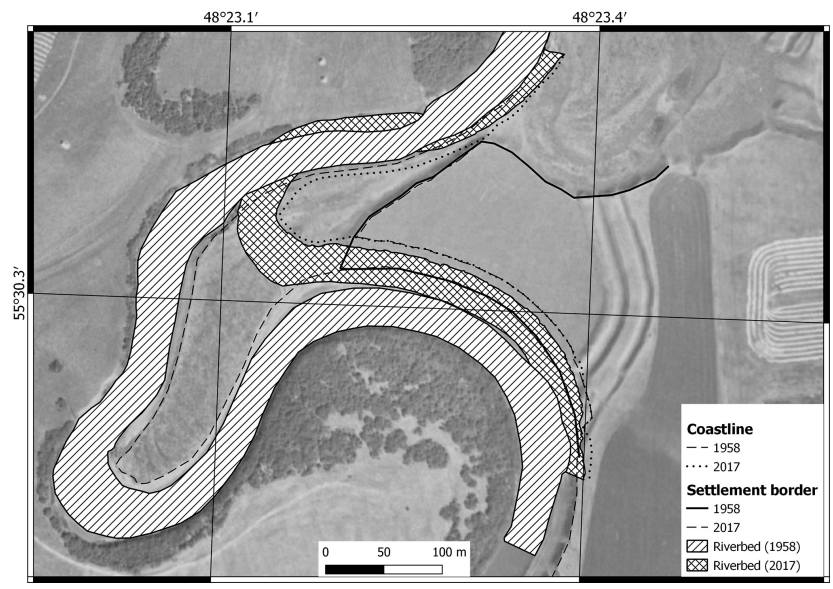

Figure 3. River channel change at the Lukovskoe fortified settlement (1958-2017).

20th century at least $30 \%$ of the settlement area and $50 \%$ of fortifications were lost. The original form of the settlement cannot be restored. The northwestern part of the monument is bordered by a low ledge $(5-6 \mathrm{~m})$. The ledge is covered by grass and no evidence of recent exogenous processes was observed. However, few paths created by cattle are cutting the ledge and leading to erosion.

The southern part of the settlement is influenced by the movement of the Kubnya river. The rates of horizontal deformations of small rivers channels flowing in loose sediments vary, typically from 0.1 to $2 \mathrm{~m} \mathrm{yr}^{-1}$. This is $2-3$ times less than average rate and 15-20 times less than the extreme values of bank erosion on large rivers (Reference). Erosion of the lower stream bank which consists of sand of the channel facies is eroded by the stream causing the upper part of the floodplain facies to collapse. The meander bend continues to extend into the settlement. From 1958-2017, the river 
bank retreated by an average of $18.8 \mathrm{~m}\left(0.32 \mathrm{~m} \mathrm{yr}^{-1}\right)$. In total, $5530.5 \mathrm{~m}^{2}$ of material was removed by the river which constitute approximately $18 \%$ of the settlement in 1958. At present, the length of fortifications is $180 \mathrm{~m}$. In the middle of the 1990s, the riverbed "shifted" $254 \mathrm{~m}$ to the northeast. Therefore, displacement of the river Kubnya in the south-east direction $\left(0.15 \mathrm{~m} \mathrm{yr}^{-1}\right)$ can be observed in the northern part of the settlement, which may soon lead to the resumption of the bank caving processes by the channel flows at this area.

\section{Conclusions}

The present study of the effect of fluvial processes on the Lukovskoe fortified settlement location showed river bank erosion accounted for a loss of approximately $1 / 5$ of the settlement. Recreation and agricultural practices (pasture) also influenced the historical settlement. More detailed study of the settlement is necessary to assess the risk of natural and anthropogenic impacts on the settlements to determine the implement protection zones for the monument and develop recommendations for security and rescue work.

Data availability. We cannot provide historical aerial photography data, as they contain State Secret. The data of the own survey with the UAV can be provided to all interested scientists upon request to the correspondence author.

Author contributions. The authors carried out work on field surveys with UAVs (PK, AK), UAV data processing and mapping (AG), inroduction and methods section and historical data analisys (IG), description of fortified settlement state and fluvial processes intensity analisys (BU).

Competing interests. The authors declare that they have no conflict of interest.

Special issue statement. This article is part of the special issue "Land use and climate change impacts on erosion and sediment transport". It is a result of the ICCE Symposium 2018 - Climate Change Impacts on Sediment Dynamics: Measurement, Modelling and Management, Moscow, Russia, 27-31 August 2018.

Acknowledgements. This work was supported by Russian Foundation for Basic Research (project No. 18-09-40114) (field survey, data processing and analisys) and performed according to the Russian Government Program of Competitive Growth of Kazan Federal University (providing historical information).
Financial support. This research has been supported by the Russian Foundation for Basic Research (grant no. 18-09-40114).

\section{References}

Akhmarov, G.: The Yapanchino fortified settlement on the river Kubna, Society of Archeology, History and Ethnography at Kazan University, XII, 179-182, 1894.

Akhmarov, G.: Report on a trip with an archaeological purpose in the summer of 1909 to Sviyazhsky and Tetyushsky districts of Kazan governorate, Society of Archeology, History and Ethnography at Kazan University, XXV, 179-182, 1910.

Fernández-Hernandez, J., González-Aguilera D., RodríguezGonzálvez P., and Mancera-Taboada J.: Image-based modelling from unmanned aerial vehicle (UAV) photogrammetry: an effective, low-cost tool for archaeological applications, Archaeometry, 57, 128-145, https://doi.org/10.1111/arcm.12078, 2015.

Gafurov, A. M.: Small catchments DEM creation using Unmanned Aerial Vehicles, IOP Conf. Ser.-Earth and Env. Sci., 107, 12005, https://doi.org/10.1088/1755-1315/107/1/012005, 2018.

Gainullin, I. I., Khomyakov, P. V., Sitdikov, A. G., and Usmanov, B. M.: Qualitative assessment of the medieval fortifications condition with the use of remote sensing data (Republic of Tatarstan), Proceedings of SPIE - The International Society for Optical Engineering, 10444, 104440X, https://doi.org/10.1117/12.2279136, 2017.

Gubaidullin, A.: Fortification in the Middle Volga in the X - the first half of the XVI century (based on archaeological research), Doctoral thesis, 2017.

Ivanov, M. A., Prischepov, A. V., Golosov, V. N., Zalyaliev, R. R., Yefimov, K. V., Kondratieva, A. A., Kinyashova, A. D., and Ionova, Yu. K.: Method of croplands dynamics mapping in river basins of the European part of Russia for the period of 19852015, Sovremennye Problemy Distantsionnogo Zondirovaniya Zemli iz Kosmosa, 14, 161-171, https://doi.org/10.21046/20707401-2017-14-5-161-171, 2017.

Kalinin, N. F. and Khalikov, A. H.: Results of archaeological work for 1945-1952 years, Works of the Kazan branch of the USSR Academy of Sciences, Historical Sciences Series, Kazan, Tatar book publishing house, 126 pp., 1954.

Nicu, I. C.: Natural risk assessment and mitigation of cultural heritage sites in North-eastern Romania (Valea Oii river basin), Area, 51, 142-154, https://doi.org/10.1111/area.12433, 2018.

Usmanov, B., Yermolaev, O., and Gafurov, A.: Estimates of slope erosion intensity utilizing terrestrial laser scanning, Proc. IAHS, 367, 59-65, https://doi.org/10.5194/piahs-367-59-2015, 2015.

Usmanov, B., Nicu, I. C., and Gainullin, I.: Monitoring and assessing the destruction of archaeological sites from Kuibyshev reservoir coastline, Tatarstan Republic, Russian Federation. A case study, J. Coast. Conserv., 22, 417-429, https://doi.org/10.1007/s11852-017-0590-9, 2018.

Vyacheslav, N.: Notes on fortified settlements, burial mounds and other ancient earth mounds in Kazan governorate, Kazan governorate printing house, 33 pp., 1874.

Yermolaev, O. P. and Avvakumova, A. O.: Cartographicgeoinformational estimation of spatio-temporal erosion dynamics of arable soils in forest-steppe landscapes of the Russian Plain, Erosion and Sediment Yields in The Changing Environment, IAHS Publication, 356, 332-337, 2012. 
Yermolaev, O. P., Gafurov, A. M., and Usmanov, B. M.: Evaluation of Erosion Intensity and Dynamics Using Terrestrial Laser Scanning, Eurasian Soil Sci., 51, 814-826, https://doi.org/10.1134/s1064229318070037, 2018. 